\title{
Environmentally Friendly Geopolymer Building Material: Production, Determination of Physical- Mechanical-Radiation Absorption Properties and Mathematical Model Approach
}

Neslihan DOGAN-SAGLAMTIMUR ( $\square$ neslihandogansaglamtimur@gmail.com )

Nigde Omer Halisdemir University https://orcid.org/0000-0001-6287-6268

Ahmet Bilgil

Niğde Ömer Halisdemir University: Nigde Omer Halisdemir Universitesi

Sefa Ertürk

Niğde Ömer Halisdemir University: Nigde Omer Halisdemir Universitesi

Vakkas Bozkurt

Niğde Ömer Halisdemir University: Nigde Omer Halisdemir Universitesi

\section{Elif Süzgeç}

Nigde Omer Halisdemir University

\section{Arife Gözde Akan}

Niğde Ömer Halisdemir University: Nigde Omer Halisdemir Universitesi

\section{Pervin Nas}

Nigde Omer Halisdemir University

\section{Betül Dikkaya}

Niğde Ömer Halisdemir University: Nigde Omer Halisdemir Universitesi

Hüseyin Çetin

Niğde Ömer Halisdemir University: Nigde Omer Halisdemir Universitesi

\section{Research Article}

Keywords: Environment, Fly ash, Geopolymer, Industrial solid waste, Building material, Radiation absorption, Waste reuse

Posted Date: March 2nd, 2021

DOl: https://doi.org/10.21203/rs.3.rs-252597/v1

License: @ (i) This work is licensed under a Creative Commons Attribution 4.0 International License. Read Full License 



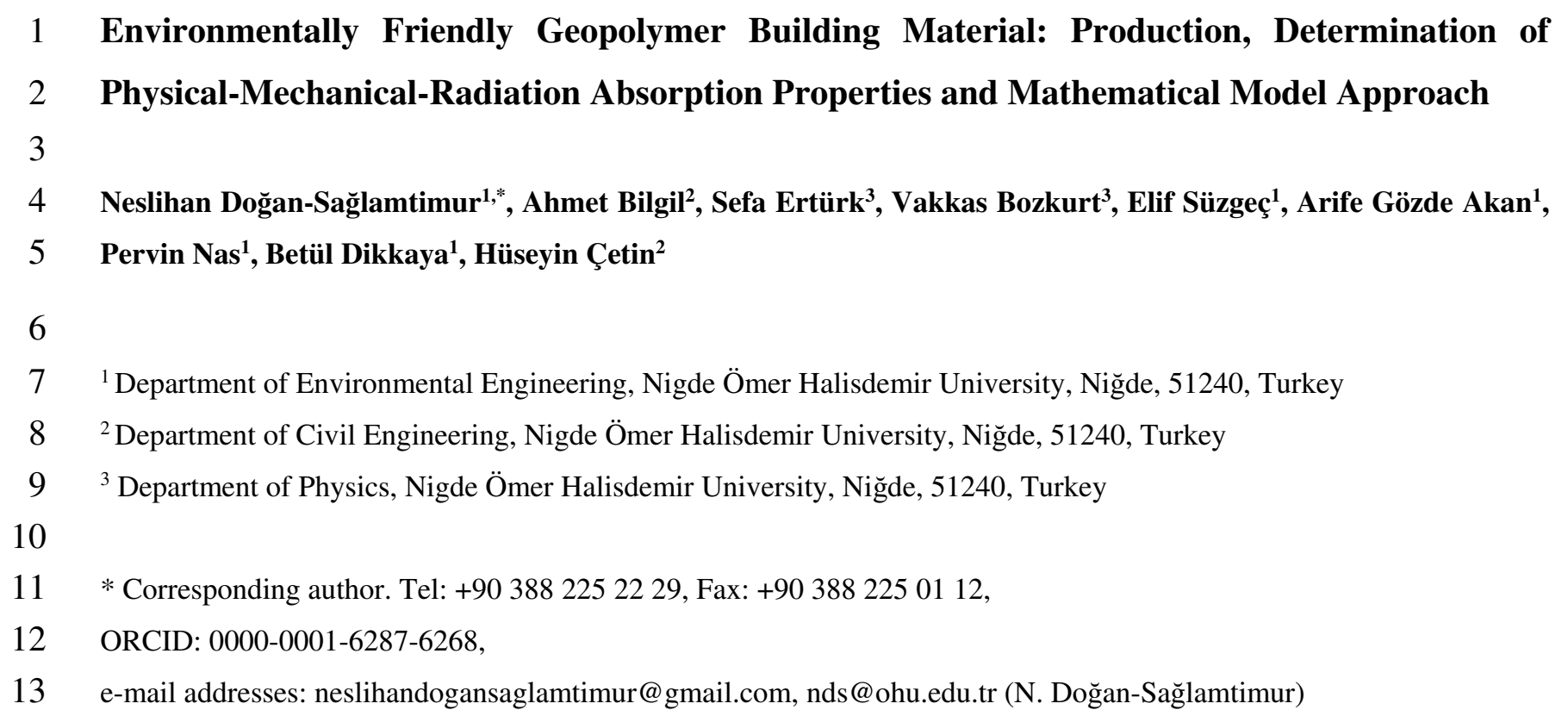

\section{Abstract}

16 Waste ashes and radiation cause important environmental and health problems. Therefore, reduction of their amount is 17 vital. In this study, physical-mechanical and radiation absorption (RA) properties of eco-friendly alkali ( $\mathrm{NaOH}$ and $18 \mathrm{Na}_{2} \mathrm{SiO}_{3}$ ) activated geopolymer building material (GPBM) produced by using the industrial solid waste class $\mathrm{F}$ fly ashes 19 (FFAs) are determined. The FFAs were supplied from thermal power plants operating in Zonguldak and Adana 20 (Turkey). The sieve analysis, loose/tight unit weight and loss on ignition analysis of the FFAs was conducted. Different 21 FFAs and alkali activator amounts were used for making GPBMs. After thermal curing in a laboratory oven at $70{ }^{\circ} \mathrm{C}$ and $22100{ }^{\circ} \mathrm{C}$, the produced GPBMs were kept to cool off to room temperature. Afterwards, compressive and flexural 23 strengths, water absorption, porosity tests and RA measurements were performed. Influence of several parameters (FFA 24 types, curing temperature and alkali ratios) on the RA properties of GPBM is discussed in this paper. According to the 25 mathematical model developed in this study, the effect of FFAs supplied from different TPPs onto RA (\%) is an 26 important issue. Because FFA quantity causes to increase RA (\%) with respect to the composed mathematical model. 27 The FFA-based GPBMs, which have a compressive strength of more than $30 \mathrm{MPa}$, have higher radiation absorption 28 (>12\%) than ordinary Portland cement-based conventional building materials (9.52\%). The highest compressive strength 29 and RA percentage were measured as $93.3 \mathrm{MPa}$ and $12.54 \%$, respectively, for the GPBMs that are (properly) suited for 30 the construction sector.

32 Keywords Environment · Fly ash · Geopolymer - Industrial solid waste · Building material · Radiation absorption · 33 Waste reuse 
The demand for building materials is increasing every day for sustaining the necessity of structure development. The global consumption of concrete is ranked second after water. When demand for structural concrete increases, the demand for Portland cement also increases. Ordinary Portland cement (OPC) production consumes both energy and natural resources. Nevertheless, OPC emits huge amounts of $\mathrm{CO}_{2}$, a greenhouse gas causing global warming, to the atmosphere. The process of calcination (which drives $\mathrm{CO}_{2}$ from $\mathrm{CaCO}_{3}$ in order to form $\mathrm{CaO}$ ) is responsible for approximately $50 \%$ of $\mathrm{CO}_{2}$ emission, while the remaining $\mathrm{CO}_{2}$ is released by energy production processes. As stated in the International Energy Agency's Greenhouse Gas R\&D Programme, production of cement releases an average $\mathrm{CO}_{2}$ emission of $0.81 \mathrm{~kg} \mathrm{CO}_{2}$ per $\mathrm{kg}$ cement produced in the world (Okoye 2016). Additionally, the vulnerability of OPC building material to acid attack (Irico et al. 2020) is a subject of concern for future durability of this binder.

Geopolymer as an alternative binder has been studied extensively in every part of the world to make the building material environmentally friendly as part of the sustainable development (Dadsetan et al. 2019; Luhar and Luhar 2020). In fact, while comparing the OPC to geopolymer, the main advantage of the latter is its chemical resistance (Luhar and Luhar 2020). Davidovits introduced the term "geopolymers" for the first time to assign a new class of three-dimensional alumino-silicate materials. He also developed fly ash (FA) based alkaline solution activated geopolymers (Davidovits 1979).

The interest towards the improvement of novel technologies for the production of higher potential geopolymer-based products has gradually increased (Koumoto 2019; Djobo et al. 2017). Geopolymeric materials are alluring since they can help to attain outstanding mechanical properties and durability (Kurtoğlu et al. 2018; Huseien et al. 2017). Moreover, geopolymer exhibits synergies (in the depollution process) which makes it cost-effective and novel in the context of removing organic pollution from water and air to protect and improve the environment (Asim et al. 2019).

Geopolymerization stems from the alumino-silica chain. The FA, industrial solid waste, composed of fine particles and released from coal fired power plants, holds higher amounts (in \%) of amorphous silica and alumina, therefore it is convenient as a source/raw material to produce geopolymer. For obtaining alumina and silica precursors, FA is generally mixed with an alkali solution. The contact with alkali solutions results in dissolution of silicate species (Arnoult et al.

63 2018; Chindaprasirt et al. 2014). Regularly, geopolymers having high-strength could be produced from class F FA 64 (Somna et al. 2011).

As an energy process, radiation can be divided into two groups: ionizing and nonionizing. The energy of ionizing radiation (per photon or particle) to ionize atoms contains sufficient energy whereas nonionizing radiation (per photon or particle) to ionize atoms is deficient. Radiation can be seen in different forms as particle alpha, beta and neutron or in electromagnetic waves such as gamma and $X$ rays (Evcin et al. 2018).

Among those radiations, neutron, $\mathrm{X}$ and gamma rays are potentially harmful and can penetrate through the walls and roofs and they can easily escape from accelerators, roofs of hospitals or environments of nuclear power plants. Normal cement as we use in our daily life and other conventional building materials do not have the ability to absorb and stop those types of radiation. Conventional concrete, which we use in our daily life, has pores and tiny particles such as 
However, shielding concrete is heavier and denser than OPC-based concrete. Therefore, medical units, nuclear power plants, and nuclear research centres use heavy concrete to obtain radioactive proof walls and roofs (Mohammed et al. 76 2014).

77 When OPC-based concrete and anti-radiation concrete are compared, we can see that anti-radiation concrete is approximately 1.5 times heavier and denser than OPC-based concrete. As a result, it can be said that heavy concrete has better absorbing substances than OPC-based concrete. Therefore, a number of studies have been performed in the last decades (Aygün 2019; Akkurt et al. 2012). For example, the effect of amount of barite or anti-radiation aggregates on the attenuation co-efficient of radioactive rays was investigated (Mohammed et al. 2014). The findings of this study showed that the attenuation coefficient is directly related to the type of material, but there is no significant influence of quantity of aggregates on the radiation absorption (RA) ability of concrete. However, there is also research available studying the design of shielding material using geopolymer with 15\% barium sulphate (Shalbi et al. 2017) and studying radiation shielding of concretes including different aggregates (Kubissa et al. 2018). Furthermore, concrete produced with heavyweight aggregates of various mineral origins can be used as absorbents for radiation (Basyigit et al. 2011).

In terms of power plants, Turkey ranks near the top 15 in the world market (Tamzok 2017) which represents a considerably high market share. In accordance with Fatih and Umit (2001) and Gorhan et al. (2008) estimates, annual amount of FA is approximately $50 \mathrm{Mt}$ in 2020. It is known that reuse, which is transformation of waste into another product in the pyramid of the waste management hierarchy, has many advantages. It is necessary to develop reuse studies within the industrial ecology concept. FA has been the subject of research and application in the world for many years. Although there are some local practices in different countries, some shortcomings exist in the literature. The vast majority of FA, which comes out in many countries, is stored in authorized warehouse sites and some of them are used in Civil Engineering applications.

The limited possibilities of usage of class F FA (FFA) in several countries necessitates the efforts to solve the waste problem both environmentally and economically. In this study, physical-mechanical properties of eco-friendly GPBMs that were produced by using class FFAs supplied from Catalagzi Thermal Power Plant (TPP) (Zonguldak, Turkey) and Isken Sugozu TPP (Adana, Turkey) as raw materials and $\mathrm{NaOH}$ and/or $\mathrm{Na}_{2} \mathrm{SiO}_{3}$ as alkali activators were determined. The irradiation was performed with Cs-137 to the FFA-based GPBMs and radiation absortion (RA) percentage of these materials was measured. A mathematical model is also developed in this study. The data was fitted to a suitable polynomial function by applying the Least-Squares method. These polynomial functions are maximized under the substance constraints to find optimum mixtures to achieve the maximum RA (\%). This study is intended to reduce the environmental problems and contribute to a circular economy and zero waste principles by means of the reuse of FFA as a raw material. It is also intended to reduce carbon footprint and global warming by courtesy of cementless geopolymer technology and specifically to produce FFA-based GPBMs having high capacity of RA (when compared to conventional building materials). 


\section{Materials}

In this study, 4x4x16 cm cementless eco-friendly GPBMs were produced by using FFAs, alkali activators and Rilem Cembureau standart sand as materials.

Chemical composition analysis of FFAs (Table 1) supplied from Catalagzi and Isken TPPs were done by using Panalytical/Zetium XRF. Morphology of these FFAs (Figure 1) were-determined by using a Zeiss/EVO 40 SEM.

118 Surface area measurements of them were done by using a Quantachrome/NOVA Touch LX4 BET. Afterwards, sieve

119 analysis, combustible material analysis and loose/tight bulk density determination of the FFAs were performed.

\section{The chemical composition analysis of FFAs}

122 The chemical composition of FFAs that have a maximum particle size of $500 \mu \mathrm{m}$ is analysed (Figure 1) and summarized

123 in Table 1. The amounts of $\mathrm{Al}_{2} \mathrm{O}_{3}$ and $\mathrm{SiO}_{2}$ are significantly higher (>20\% and 40\%) and the other components are much

124 less $(<7 \%)$ in Catalagzi TPP and Isken TPP FFAs. The ratio of $\mathrm{SiO}_{2} / \mathrm{Al}_{2} \mathrm{O}_{3}$ ranges between 2.08 to2.90 and the content of silica+alumina ranges from 80.16 to $83.74 \%$ in FFAs of Catalagzi and Isken TPPs, respectively. $\mathrm{CaO}$ amounts, in the case of Catalagzi and Isken TPPs, were less than 10\% in these FFAs (ASTM C618). These are the main ingredients of the geopolymeric reaction and they are within the range of values reported by other scientists (Fernández-Jiménez and Palomo 2005; Diaz et al. 2010). By means of their chemical composition, FFAs of Catalagzi and Isken TPPs are very suitable to produce GPBM. This is the main factor in selecting these two among many TPP FFAs in Turkey. Loss on ignition (LOI) is a critical parameter when evaluating the geopolymerization potential for a given FFA. LOI values were determined as 1.52 and $1.78 \%$ for the FFAs of Catalagzi and Isken TPPs, respectively (Table 1).

[Table 1 near here]

\section{4}

\section{Scanning electron microscopy (SEM) analysis of FFAs}

Morphology of FFAs were determined by using a scanning electron microscope (SEM). Results given in Figure 1 indicate that the surface morphology of Catalagzi TPP FFA is clearly different than that of Isken TPP FFA.

[Figure1 near here]

\section{Surface area measurement (BET) of FFAs}

143 The BET instrument can detect surface area measurements, micro, meso and macro pore size and distribution of the pore

144 size at low pressures and high resolution by the physical absorption method in solid or powder samples. BET values 145 were determined as 1.11 and $2.26 \mathrm{~m}^{2} / \mathrm{g}$ for FFAs of Catalagzi and Isken TPP (Table 2). 


\section{Sieve analysis of FFAs}

149 Sieve analysis of the FFAs was performed according to TS EN 933-10. It was observed that FFA of Isken TPP was finer

150 than FFA of Catalagzi TPP (Figure 2).

[Figure 2 near here]

\section{Combustible material of FFAs}

155 For combustible material calculation of the FFA, firstly crucible tare was weighted. $20 \mathrm{~g}$ of the FFA was put into a 156 crucible and left in the oven at $105{ }^{\circ} \mathrm{C}$ in the oven to dry. The sample was weighed (x) and put in a muffle furnace at 750 $157{ }^{\circ} \mathrm{C}$ for 2 hours, cooled off to room temperature and weighed again (y). Combustable material is calculated by the 158 formula: $[(\mathrm{x}-\mathrm{y}) / \mathrm{x}]^{*} 100$. In this study, combustible material amounts were determined as $7 \%$ and $9 \%$, respectively, for FFAs of Catalagzi and Isken TPP (Table 2).

\section{Loose and tight UW of FFAs}

162 Bulk density is dependent on the granulometry of the aggregate, the amount of faulty materials, the position of the 163 specimen and the specific weight of the aggregate. The loose and tight bulk density values were calculated as given in 164 Table 2.

[Table 2 near here] (by mass). Rilem Cembureau standard sand (Table 3) that complies with TS EN 196-1 specification has a specific gravity of 2.56 and density of $1.35 \mathrm{~kg} / \mathrm{dm}^{3}$.

[Table 3 near here]

\section{Method}

176 To make geopolymer paste by using only FFA, separate and normal mixing methods were used. For separate mixing, 177 FFA was mixed with $\mathrm{NaOH}$ for 10 minutes to enable leaching of ions; subsequently $\mathrm{Na}_{2} \mathrm{SiO}_{3}$ solution was added to the 178 mixture. Since the mixtures were relatively viscous/fluid, only a short period of mixing time was needed to obtain a 179 perfect/good mixture. For normal mixing, FFA, $\mathrm{NaOH}$ and $\mathrm{Na}_{2} \mathrm{SiO}_{3}$ solutions were mixed together for 1 min [5]. For 180 this study, a normal mixing procedure was preferred because it gave better strength mortar than the separate mixing 181 procedure/method. On the other hand, FFA and Rilem Cembureau standard sand were mixed in a mixer approximately 182 for 3 minutes to make geopolymer paste. $\mathrm{Na}_{2} \mathrm{SiO}_{3}$ and $\mathrm{NaOH}$ were mixed together, subsequently dry materials were 183 added and then it was mixed again for 3 minutes. The mixtures' workability was determined in terms of flow 184 characteristics (ASTM C1437-15). 
FFA-chemical activator mixture rates (Table 4) were determined to produce GPBM samples. The mixtures were poured into moulds with dimensions of $4 \times 4 \times 16 \mathrm{~cm}$. GPBMs were cured at $70^{\circ}$ and $100^{\circ} \mathrm{C}$ for 24 hours. After completing

187 the thermal curing period the samples were de-moulded and kept at room temperature (Figure 3) until testing time at 7-, 188 28- and 90-days.

Main mechanical-physical properties (flexural strength, compressive strength, bulk density, water absorption, porosity) were determined and then RA status was measured in GPBMs produced in different combinations at different mixing ratios and curing temperatures (Table 4) according to related ASTM and TS-EN standards.

\section{Physical and mechanical tests}

196 For the calculation of bulk density, following equation (Eq. 1) was used.

$198 \mathrm{~m}_{\text {dry.u: }}$ : Air-dried bulk density

$199 \quad \mathrm{~V}_{\mathrm{g} . \mathrm{u}}$ : Gross volume of the samples

$200 \quad \rho_{\text {g.u }}$ : Bulk density

$201 \quad$ Flexural and compressive strengths of GPBMs

202 Flexural strength, also known as modulus of rupture, or bending strength, or transverse rupture strength is a material 203 property, defined as the stress in a material just before it yields in a flexure test. In this study, the flexural strength test 204 was done according to ASTM C348-14. The compressive strength test, which is a mechanical test measuring the 205 maximum amount of compressive load a material can bear before fracturing, was done according to ASTM C349-14.

$206 \quad$ Water absorption and porosity of GPBMs

207 Using the data obtained, with the help of the following equations (Eqs. 2 and 3), water absorption of the samples by 208 mass $\left(S_{k}\right)$ and by volume $\left(S_{h}\right)$ were calculated.

$209 \quad S_{k=\frac{G_{d}-G_{k}}{G_{k}} \times 100}(\%)$

$210 \mathrm{~S}_{\mathrm{k}}$ : The percentage of water absorption by mass

$211 \quad \mathrm{G}_{\mathrm{d}}$ : Saturated mass

$212 \mathrm{G}_{\mathrm{k}}$ : Dried mass

$213 \quad S_{h=\frac{G_{d}-G_{k}}{G_{d}-G_{d s}} \times 100(\%)}$

$214 \mathrm{~S}_{\mathrm{h}}$ : The percentage of water absorption by volume

$215 \mathrm{G}_{\mathrm{ds}}$ : Sample weight (According to Archimedes' water scale)

216 Porosity or void fraction is a measure of the void (i.e. "empty") spaces in a material, and is a fraction of the volume of 217 voids over the total volume.

$218 \quad \underline{\text { RA of the GPBMs }}$

219 In order to determine the RA of GPBMs, a lattice system was designed consisting of nested lead plates in order to avoid 220 uncontrolled radiation (Figure 4, 5). RA measurements were performed using a Geiger-Müller counter with a Cs-137 221 radioactive source covered with a 4-mm thick lead radiation shield (LRS) cage. The schematic respresentation of the 
experimental-setup is given in Figure 4. The average values of RA for GPBMs were tested. The results for radiation source of Cs-137 are given in Table 4.

[Figure 4 near here]

In the first step, the Geiger-Müller counter is placed outside the LRS cage and detects the amount of gamma rays emitted from the radioactive source ( $5 \mathrm{~cm}$ away from the Geiger-Müller counter) in the absence of GPBMs (Figure 4, Figure 5.a). As can be seen in the figure, there is nothing between the radioactive source (Cs-137) and the Geiger-Müller counter. By this way, the Geiger-Müller counter directly measured the amount of radiation from the radioactive source. In the second step, a GPBM was placed between the radioactive source and the Geiger-Müller counter (Figure 4, Figure 5.b). Finally, the LRS cage is closed with a lid and the Geiger-Müller counter measured the radiation (Figure 5.c).

[Figure 5 near here]

The measurements were performed by reading the value on the counter that detects gamma-rays emitted from the radioactive source (Cs-137) that were placed behind the sample. In both measurements, data was taken for one hour and a ratio was determined by averaging the two results obtained. Thus, the amount of radiation absorbed by the measured sample was determined proportionally. This procedure was performed for all the GPBM samples, and the results are listed in Table 4.

\section{The Least-Squares Method and curve fitting}

Deviations during experiments are inevitable. But extreme deviations due to different measurement points should be eliminated. The least-square method presents a method to overcome the deviation in experimental measurement data. This technique aims to minimize the data points and results in a fitted curve [32]. In order to find an optimum fitted curve, let the observed data points and the fitted curve be denoted by $\left(x_{i}, y_{i}\right)$ and $q\left(x_{i}\right)(i=1,2,3 . . n)$. The $\mathrm{i}^{\text {th }}$ point error $\varepsilon_{i}$ which gives the difference between $y_{i}$ and $q\left(x_{i}\right)(i=1,2,3 . . n)$ can be specified by;

250 If $q\left(x_{i}\right)$ is defined as the polynomial function, the total error can be expressed as follows;

$251 \quad \sum_{i}^{N} \varepsilon_{i}=\sum_{i}^{N}\left(y_{i}-q\left(x_{i}\right)\right)$

$\sum_{i}^{N} \varepsilon_{i}=\sum_{i}^{N}\left(y_{i}-\left(\alpha_{0}+\alpha_{1} x_{i}+\alpha_{2} x_{i}^{2}+\cdots+\alpha_{n} x_{i}^{n}\right)\right)$

253 In order to obtain the most suitable fit curve for the data set, the square of the total error for points $E$ should be at 254 a minimum. This can be written as;

$255 E=\sum_{i}^{N}\left(\varepsilon_{i}\right)^{2}=\sum_{i}^{N}\left(y_{i}-\left(\alpha_{0}+\alpha_{1} x_{i}+\alpha_{2} x_{i}^{2}+\cdots+\alpha_{n} x_{i}^{n}\right)\right)^{2}$

256 In order to achieve a higher order degree curve fitting, $E$ should be at a minimum. Therefore, each partial 257 derivative for each indefinite coefficient of $E$ needs to be zero. This can be expressed as;

$258 \frac{\partial E}{\partial \alpha_{0}}=0=-2 \sum_{i}^{n}\left(y_{i}-\left(\alpha_{0}+\alpha_{1} x_{i}+\alpha_{2} x_{i}^{2}+\cdots+\alpha_{n} x_{i}^{n}\right)\right)$ 
$\frac{\partial E}{\partial \alpha_{n}}=0=-2 \sum_{i}^{n}\left(y_{i}-\left(\alpha_{0}+\alpha_{1} x_{i}+\alpha_{2} x_{i}^{2}+\cdots+\alpha_{n} x_{i}^{n}\right)\right) x_{i}^{n}$

262 If the equalities above are arranged for an nth degree curve, the $(n+1)$ th particle and the undetermined

263 coefficients can be calculated. In this case, the curve and undefined coefficients can be calculated (Uzun 2011) and the

264 equations can be written as given below;

$265 \quad \sum_{n=1}^{n} q\left(x_{i}\right) \cdot \frac{\partial q\left(x_{i}\right)}{\partial \alpha_{k}}=\sum_{n=1}^{n} y_{i} \cdot \frac{\partial q\left(x_{i}\right)}{\partial \alpha_{k}}$

\section{Optimization problem and methods}

Numerical algorithms for nonlinear constraint optimization can mainly be divided into two methods namely gradient based methods and direct search methods. Whereas gradient-based optimization methods depend on the first (gradient) and second derivatives (Hessian), direct search methods do not use the derivatives. The convergence of the direct search methods is slower than the convergence of the gradient-based methods, but the former method is more robust and has more tolerance to noise in the objective function and constraints. In this study, two different numerical direct search methods are used namely the Simulated Annealing (SA) and the Differential Evolution (DE) algorithm (Champion and Strzebonski 2008).

The DE method was firstly developed by Storn and Pricein (Storn and Price 1997). The objective function in this method should be defined under the equality or inequality constraints. Considering these constraints, in the first step, the initial population determined with the target vector and donor vector is created by mutation. After that, in order to define the test vector for the new generation, the target vector and donor vectors are compared with the purpose of choosing the lower one. Therefore, if this test vector is lower than the target vector, the optimization algorithm is ended, else the procedure must return to the mutation step for the production of a new generation. On the other hand, the SA algorithm is a random optimization method that depends on heating the metal to high temperatures and then setting it free for cooling slowly (annealing). This process brings the atoms of the metal to a lower energy level so that the metal can be tougher. Thanks to the annealing procedure, the optimum point avoids the local point.

\section{Prediction of mathematical model obtained from experiments}

Considering the results of the experiments which are depicted in Table 4, optimum curves are fitted as multivariable polynomials functions for RA (\%). This fitting aims to predict the RA\% of GPBMs without experiments. In this prediction a, b, c and d are quantities of $\mathrm{NaOH}, \mathrm{Na}_{2} \mathrm{SiO}_{3}$, FFAs and sand, respectively. The optimum fitted curve fitting polynomial functions are expressed by using the command "Fit" in Wolfram Mathematica 11 Program.

For GPBMs produced from FFAs of Catalagzi TPP at $70{ }^{\circ} \mathrm{C}$, RA (\%) is expressed in Eq. 12 
$\left(1.17738 \times 10^{-12}\right) c^{4}-\left(4.49614 \times 10^{-13}\right) d^{4}+\left(6.81304 \times 10^{-8}\right) b^{3}-\left(9.42366 \times 10^{-10}\right) c^{3}+(5.55359 \times$ $\left.10^{-10}\right) d^{3}+\left(1.45796 \times 10^{-5}\right) b^{2}-\left(5.88341 \times 10^{-7}\right) c^{2}+\left(1.14292 \times 10^{-6}\right) d^{2}+\left(1.88691 \times 10^{-3}\right) b-$ $\left(1.57535 \times 10^{-4}\right) c+\left(1.33691 \times 10^{-3}\right) d+1.24475 \times 10^{-1}$

For GPBMs produced from FFAs of Catalagzi TPP at $100{ }^{\circ} \mathrm{C}$, RA $(\%)$ is expressed in Eq. 13

$\mathrm{RA}(\%)=8.87011 \times 10^{-1}-\left(1.47085 \times 10^{-2}\right) a-\left(1.39286 \times 10^{-5}\right) a^{2}+\left(5.91645 \times 10^{-9}\right) a^{3}+(4.20831 \times$ $\left.10^{-11}\right) a^{4}+\left(1.07088 \times 10^{-13}\right) a^{5}-\left(2.64208 \times 10^{-3}\right) b-\left(6.1538 \times 10^{-6}\right) b^{2}+\left(1.18374 \times 10^{-8}\right) b^{3}+$ $\left(1.28551 \times 10^{-10}\right) b^{4}+\left(5.33933 \times 10^{-13}\right) b^{5}+\left(1.14801 \times 10^{-3}\right) c+\left(1.12699 \times 10^{-6}\right) c^{2}+(1.05019 \times$ $\left.10^{-9}\right) c^{3}+\left(9.8909 \times 10^{-13}\right) c^{4}+\left(9.48881 \times 10^{-16}\right) c^{5}+\left(9.94322 \times 10^{-4}\right) d+\left(1.05721 \times 10^{-6}\right) d^{2}+(1.0887 \times$ $\left.10^{-9}\right) d^{3}+\left(1.10331 \times 10^{-12}\right) d^{4}+\left(1.11359 \times 10^{-15}\right) d^{5}$

For GPBMs produced from FFAs of Isken TPP at $70{ }^{\circ} \mathrm{C}$, RA (\%) is expressed in Eq. 14 $\mathrm{RA}(\%)=1.9303-\left(2.94395 \times 10^{-3}\right) a-\left(2.10911 \times 10^{-5}\right) a^{2}-\left(5.14918 \times 10^{-8}\right) a^{3}-\left(8.67883 \times 10^{-11}\right) a^{4}-$ $\left(9.49116 \times 10^{-14}\right) a^{5}-\left(7.62291 \times 10^{-3}\right) b-\left(1.69901 \times 10^{-5}\right) b^{2}-\left(1.49812 \times 10^{-8}\right) b^{3}+(3.67679 \times$ $\left.10^{-12}\right) b^{4}+\left(4.78592 \times 10^{-14}\right) b^{5}+\left(2.43782 \times 10^{-3}\right) c+\left(2.35335 \times 10^{-6}\right) c^{2}+\left(2.10219 \times 10^{-9}\right) c^{3}+$ $\left(1.88094 \times 10^{-12}\right) c^{4}+\left(1.72488 \times 10^{-15}\right) c^{5}+\left(2.62016 \times 10^{-3}\right) d+\left(2.29045 \times 10^{-6}\right) d^{2}+(1.22139 \times$ $\left.10^{-9}\right) d^{3}-\left(6.33071 \times 10^{-13}\right) d^{4}-\left(3.23822 \times 10^{-15}\right) d^{5}$

For GPBMs produced from FFAs of Isken TPP at $100{ }^{\circ} \mathrm{C}$, RA (\%) is expressed in Eq. 15

$\mathrm{RA}(\%)=3.53809+\left(6.06097 \times 10^{-3}\right) a-\left(3.78929 \times 10^{-6}\right) a^{2}-\left(3.65212 \times 10^{-8}\right) a^{3}-\left(8.36025 \times 10^{-11}\right) a^{4}+$ $\left(7.68186 \times 10^{-3}\right)-\left(6.65835 \times 10^{-6}\right) b^{2}-\left(3.06929 \times 10^{-8}\right) b^{3}-\left(5.32099 \times 10^{-11}\right) b^{4}-(1.56723 \times$ $\left.10^{-14}\right) b^{5}+\left(2.01803 \times 10^{-3}\right) c+\left(5.98923 \times 10^{-7}\right) c^{2}-\left(6.45403 \times 10^{-11}\right) c^{3}-\left(2.97268 \times 10^{-13}\right) c^{4}-$ $\left(3.5863 \times 10^{-16}\right) c^{5}-\left(8.17871 \times 10^{-3}\right) d-\left(5.39477 \times 10^{-6}\right) d^{2}+\left(2.12577 \times 10^{-10}\right) d^{3}+\left(8.61754 \times 10^{-12}\right) d^{4}$ (15)

By calculating the optimum mixture of substances, the predicted equations expressed above with the purpose of 318 lower bounds expressed as below;

$0 \leq \mathrm{b} \leq 400 \mathrm{~g}$

$0 \leq \mathrm{c} \leq 1000 \mathrm{~g}$

$3220 \leq \mathrm{d} \leq 800 \mathrm{~g}$

$0 \leq \mathrm{a}+\mathrm{b} \leq 500 \mathrm{~g}$

$0 \leq \mathrm{c}+\mathrm{d} \leq 1200 \mathrm{~g}$

325 According to GPBMs produced from FFAs of Catalagzi and Isken TPPs at 70 and $100{ }^{\circ} \mathrm{C}$, respectively, Figure 6 (a), (b), (c), (d), (e), (f), (g) and (h) depict the RA (\%) optimization process with respect to design step numbers by using SA and DE methods. These figures show how RA (\%) converge to a maximum during the optimization.

329 [Figure 6 near here] 
After the optimization process for GPBMs produced from FFAs of Catalagzi and Isken TPPs at $70{ }^{\circ} \mathrm{C}(\mathrm{CTPP}-70$ and ITPP-70) and $100{ }^{\circ} \mathrm{C}$ (CTPP-100 and ITPP-100), respectively, the unknown coefficients of the predicted polynomial functions and optimum values of the RA\% are shown in Table 5.

[Table 5 near here]

Considering the GPBMs produced from FFAs of Catalagzi and Isken TPPs at 70 and $100{ }^{\circ} \mathrm{C}$, respectively, the setting of the constant quantity of $\mathrm{NaOH}$ and sand as calculated according to the maximum point, the variation of RA (\%) with respect to $\mathrm{Na}_{2} \mathrm{SiO}_{3}$ (g) and FFA (h) in three-dimensions and contour plots are shown in Figures 7 (a), (b), (c) and (d). As seen in Figure 7 (a) and (b), while an increasing amount of Catalagzi TPP FFA in GPBM cured at $70{ }^{\circ} \mathrm{C}(\mathrm{g})$ causes an increase in RA (\%), after a certain amount of $\mathrm{N}_{\mathrm{a} 2} \mathrm{~S}_{\mathrm{i}} \mathrm{O}_{3}$ it decreases and minimizes the RA (\%). After this minimum point,

342 the $\mathrm{Na}_{2} \mathrm{SiO}_{3}(\mathrm{~g})$ quantity causes a rise in RA (\%). According to GPBMs produced from FFAs of Catalagzi TPP at $100{ }^{\circ} \mathrm{C}$,

343 Figure 2 (c) and (d) shows that RA (\%) increases with FFA amount and increases also with a certain quantity of $344 \mathrm{Na}_{2} \mathrm{SiO}_{3}(\mathrm{~g})$. As seen in Figure 2 (e) and (f) for GPBMs produced from FFAs of Isken TPP at $70{ }^{\circ} \mathrm{C}$, increasing the FFA 345 amount causes to an increase in RA (\%) while an increasing $\mathrm{Na}_{2} \mathrm{SiO}_{3}$ (g) quantity leads to a decrease in RA (\%). 346 According to GPBMs produced from Isken TPP FFA at $100{ }^{\circ} \mathrm{C}$, Figure $2(\mathrm{~g})$ and $(\mathrm{h})$ demonstrate that certain quantities 347 of FFA and $\mathrm{Na}_{2} \mathrm{SiO}_{3}$ lead to a rising RA (\%). However, after the maximum point of the figure, the quantity of these variables causes a decrease in RA (\%).

\section{Results and discussion}

This study brings solutions for the environmental problems of FFA, the industrial solid waste caused by burning coal, through the production of GPBMs with improved physical-mechanical properties. By ensuring the reuse of waste ash, FFAs obtained from Catalagzi and Isken TPPs operating in Turkey were used. This production is important in terms of being able to contribute to the economy of the country, as well as being environmentally-friendly. Producing ecofriendly building materials having high RA capacity is necessary, since radiation is harmful to human health. For this reason, the RA capacity (percentage) of the GPBM was determined by using a new measurement system consisting of a LRS cage designed for the first time in the related literature.

The compressive strength of the concrete is of vital importance for the structural integrity of the reinforced concrete

362 construction phase and after the construction is completed in terms of control and evaluation. Along with the alteration 363 of standards and regulations, determination of compressive strength of the concrete has become more important for both 364 control and evaluation (Demirel 2015). "Compressive strength" is the most commonly used (and the most popular) 365 criterion in engineering applications. The compressive strength value of the concrete is taken as the basis for almost all 366 building designs. In many buildings, it is assumed that the most important load on the concrete is pressure stress (Yalcin 367 2020). For this reason, in this study, GPBMs with the best compressive strength values (>30 MPa) amongst 169 
produced materials are selected. The range of compressive strength is in good agreement with the literature studies and shows that the compressive strength of geopolymer does not significantly change with age (Mermerdaş et al. 2017).

370 Compressive strength values of GPBMs produced in this study are presented in Table 4 along with their flexural 371 strength, bulk density, water absorption, porosity and RA.

[Table 4 near here]

Radiation can cause serious harm for environment and humans unless effective shielding is provided. Even though determination of RA in GPBM is important, there are only a limited number of studies related to this parameter. Considering mixtures, combination and design, GPBM production in this study is different from the studies in the literature. Additionally, determination of RA by using a newly designed LRS cage has not been previously studied in the literature.

In this study, FAs are activated through grinding after by curing with a thermal processes and using alkali activators. The water used in the mixing phase during the production of geopolymer is used for the workability of the mixture. When the water leaves the geopolymer during the curing process, it creates discontinuous nano-voids. This situation gives lightweight properties to GPBMs (bulk densities of them are below $2 \mathrm{~g} / \mathrm{cm}^{3}$ ).

RA values of conventional building materials produced with OPC were determined as $9.52 \%$. In this study, cementless GPBM having higher RA capacity $(12.54 \%)$ was produced. The highest RA values were measured in the $2^{\text {nd }}$ and $11^{\text {th }}$ GPBMs produced by using FFAs of Catalagzi and Isken TPP. In these materials, alkali activator ratios $\left(\mathrm{Na}_{2} \mathrm{SiO}_{3} / \mathrm{NaOH}\right)$ are higher than 2. GPBMs produced by using FFAs have higher RA percentage values than the conventional building materials produced by using OPC without any waste.

According to the mathematical model developed in this study, the effect of FFAs supplied from different TPPs onto RA (\%) is an important issue. Because FFA quantity causes an increase in RA (\%) with respect to the this model.

\section{Conclusions}

$\mathrm{NaOH}$ and/or $\mathrm{Na}_{2} \mathrm{SiO}_{3}$-activated FFA geopolymers, cured at 70 and $100{ }^{\circ} \mathrm{C}$, were produced in this study. Based on the research carried out, it can be concluded that GPBMs can have better engineering properties than the corresponding properties of conventional OPC building material (C30). Also, there is an urgent need to produce an alternative to 398 building material with adequate strength in order to make construction industry more eco-friendly and sustainable. 399 Materials of this type, however, are used in specific areas, as a kind of special materials, due to their unique properties 400 such as mechanical, chemical or fire resistance (Davidovits 2020; Pacheco-Torgal et al. 2008). Radiation damages the 401 cells making up the human body and causes serious diseases and health problems. Therefore, it is important to know if 402 such material is also beneficial for radiation protection. For this reason, RA rates of the materials produced in this study 403 were determined. 
In this study, the Least-Squares Method is used to fit the obtained data to a suitable polynomial function for GPBMs including different amounts of $\mathrm{NaOH}, \mathrm{Na}_{2} \mathrm{~S}_{\mathrm{i}} \mathrm{O}_{3}(\mathrm{~g})$, sand and FFAs supplied from Catalagzi and Isken TPPs. Therefore, a mathematical model is developed to predict RA (\%) without conducting experiments. These polynomial functions are maximized under the substance constraints to find optimum mixtures to achieve the maximum RA (\%). When $\mathrm{NaOH}$ and sand quantity are taken stable in the optimum point, $\mathrm{RA}(\%)$ variation is examined with respect to $\mathrm{Na}_{2} \mathrm{~S}_{\mathrm{i}} \mathrm{O}_{3}$ and FFA quantity.

In terms of environmental, construction, chemical and health technologies; basically some important gains are considered since FFA is transformed into geopolymer building material (GPBM). These are (i) use of chemical binders

$412\left(\mathrm{NaOH}\right.$ and/or $\left.\mathrm{Na}_{2} \mathrm{SiO}_{3}\right)$ instead of the cement, which accounts for a certain part of the World's greenhouse gas emission 413 (especially $\mathrm{CO}_{2}$ ) during its production, (ii) use of waste FFAs instead of the natural aggregate, (iii) being a good 414 alternative in finding solutions for environmental problems, especially based on FA, on a national and international 415 scale, (iv) being an appropriate product for industrial symbiosis besides providing economic benefits, (v) by 416 transforming FAs which are harmful to the environment into GPBM instead of indiscriminately dumping in nature, the existing pollution problem of the environment is solved.

418 Some important findings and conclusions of this study are:

419 (a) Because a significant part of the reaction occurs at the particle-liquid interface, the finer the particles get the greater 420 is the surface area will be and the more reactive is the FA.

421 (b) Based on the present study, GPBMs with total aggregate content of 70-80\% by volume, $\mathrm{NaOH}$ molarity of 12 , $422 \mathrm{Na}_{2} \mathrm{SiO}_{3} / \mathrm{NaOH}$ ratio of 1-2.5 when cured for $24 \mathrm{~h}$ at 70 and $100{ }^{\circ} \mathrm{C}$ gave an average compressive strength of 40.62 and $42344.1 \mathrm{MPa}$ for Catalagzi TPP FFAs and 62.8 and $57.7 \mathrm{MPa}$ for Isken TPP FFAs, respectively, after thermal curing (28 ${ }^{\text {th }}$ 424 day).

425 (c) Results indicated that when compared to Catalagzi TPP FFAs, Isken TPP FFAs gave higher strength GPBMs.

426 (d) Rilem-Cembureau standard sand, which was used as filler material with FFAs, causes an increase in bulk density 427 values.

428 (e) As reported by the previous studies (Weng and Sagoe-Crentsil 2007; Sagoe-Crentsil and Weng 2007), it was 429 determined in the present study that an increase in compressive strength was due to the change in the microstructure of 430 the geopolymer, which was influenced by the quantity of $\mathrm{Na}_{2} \mathrm{SiO}_{3}$, with exception of GPBMs produced using Isken TPP 431 FFAs at in $100{ }^{\circ} \mathrm{C}$ curing temperature. Therefore, increasing the $\mathrm{NaOH}$ concentration resulted in a decrease in the 432 strength of the geopolymer due to early precipitation of aluminosilicate products.

433 (f) Increasing the chemical activator did not increase the compressive strength of these materials.

434 (g) The highest compressive strength was measured as $93.3 \mathrm{MPa}$ in the geopolymer specimen produced with $\mathrm{NaOH}$ $435(10 \%)$ in $100^{\circ} \mathrm{C}$ at 28 day.

436 (h) The highest compressive strength values were measured at 28 days. Therefore, it was concluded that the geopolymer 437 material gained strength with time.

438 (i) The values of the bulk density, porosity, water absorption and compressive strength for the best geopolymer 439 specimen having higher RA percentage were $2.01 \mathrm{~g} / \mathrm{cm}^{3}, 12.39 \%, 19.91$ and $57.3 \mathrm{MPa}$, respectively. 
440 (j) Eco-friendly GPBMs having high compressive strength, low bulk density and high RA capacity possess an important 441 feature in providing high strength and RA capacity (for the protection of human health against radiation) in lightweight 442 construction material.

443 k) Considering the proposed mathematical model, whereas increasing the quantity of Catalagzi TPP FFA of GPBM 444 cured at $70^{\circ} \mathrm{C}$ increases the RA (\%), a certain amount of $\mathrm{Na}_{2} \mathrm{SiO}_{3}(\mathrm{~g})$ decreases and minimizes the RA (\%). First the 445 polynomial Function reaches a to minimum of $\mathrm{Na}_{2} \mathrm{SiO}_{3}$ quantity, after which $\mathrm{Na}_{2} \mathrm{SiO}_{3}$ causes a rise in $\mathrm{RA}(\%)$ and it has 446 a positive contribution. Catalagzi FFA of GPBM cured at $70{ }^{\circ} \mathrm{C}$ is determined to be very effective to increase the RA 447 (\%).

448 1) Considering the proposed mathematical model and GPBM produced from Catalagzi TPP FFA at $100{ }^{\circ} \mathrm{C}$, RA $(\%)$ 449 increases with both ash and $\mathrm{Na}_{2} \mathrm{SiO}_{3}$ quantity.

$450 \mathrm{~m})$ For GPBM produced from Isken TPP FFA at $70{ }^{\circ} \mathrm{C}$, adding more ash causes higher RA (\%). However, increasing the $451 \quad \mathrm{~N}_{\mathrm{a} 2} \mathrm{~S}_{\mathrm{i}} \mathrm{O}_{3}$ quantity has a negative contribution to the RA\% in the mathematical model.

452 n) In the proposed mathematical model, both the quantities of $\mathrm{Na}_{2} \mathrm{SiO}_{3}$ and Isken TPP FFA of GPBM cured at $100^{\circ} \mathrm{C}$ 453 increase the RA (\%). However, the quantity of these variables leads to a decrease in RA (\%) after the optimum point.

In former studies, it was reported that the design and production of heavy concrete is needed to obtain better RA 455 capacity and concrete produced with heavyweight aggregates of various mineral origins can be used as absorbents for 456 radiation [20]. Heavy concrete whose density is 2900 and $6000 \mathrm{~kg} / \mathrm{m}^{3}$ is the most common material used in radiation 457 shielding. In this study, GPBMs having bulk densities below $2 \mathrm{~g} / \mathrm{cm}^{3}\left(<2000 \mathrm{~kg} / \mathrm{m}^{3}\right)$ were produced, which are 458 considered lightweight materials. Innovative aspects of this study are (i) to produce GPBMs that have high compressive 459 strength and RA capacity despite having lower bulk density compared to conventional concrete due to its nano-void 460 structure and (ii) to determine RA percentages of GPBMs for the first time in the literature by using a newly designed 461 lattice system consisting of nested lead plates (LRS cage). By courtesy of this study, certain steps are thought to be taken 462 in order to boost the availability and effectiveness of FFA in production of building material having higher capacity to 463 absorb radiation. It is predicted that, by applying the zero waste production principle, this study will contribute to the 464 solution of the industrial solid waste problem causing harm to human health. This paper also provides a missing piece of 465 the puzzle, which is needed in a transition to a fully circular economy and zero waste. (Nigde, Turkey) for providing suitable working conditions to incubate the ideas in this study. We thank ÇiMSA, one of the leading companies of Turkish cement industry, which supports this study and Dr. Adnan GÜVEN and Gökhan ARIKOĞLU, former and present managers of the ÇiMSA Niğde Plant. We also acknowledge Dr. Fatih ERDURCAN for improving the text.

Authors' Contributions NDS was Project Turkey manager, and was a major contributor in conceptualization, formal analysis, investigation, methodology and writing the manuscript, BS coordinated geopolymer production, SE coordinated the design of LRS cage system for radiation absorption experiments and edited the manuscript, VB conducted radiation absorption experiments, ES, GA, PN and BD performed geopolymer and radiation absorption experiments, HÇ made mathematical modelling for this study. Finally, all the authors read and approved the final manuscript. 
Funding The geopolymer results of this study is a part of the project "Development of eco-friendly composite materials based on geopolymer matrix and reinforced with waste fibers" funded by the European Commission, within the $7^{\text {th }}$ Framework Programme for Research and Technology Development (FP7), Topic \#02: Waste management, recycling and urban mining (Project No. ELAC2015/T02-0721) under the ERANet-LAC: Latin America, Caribbean and European Union and supported by a grant of the Turkish Scientific and Technological Research Council of Turkey (TUBITAK). The Turkish project number is 116Y549. The RA part of this study is supported by TUBITAK 2209/B Programme, project grant no. 1139B411701722.

Data Availability The datasets used and/or analyzed during the current study are available from the corresponding author on reasonable request.

\section{Compliance with ethical standards}

Ethical Approval Not applicable

Consent to Participate All authors declare that they participate in this work.

Consent to Publish All authors mutually consent for the manuscript to be published on the ESPR Journal, if it could be accepted by the ESPR Journal. Co-authors confirm the corresponding author and the order of authors are correct at submission.

Competing Interest The authors declare that there is no conflict of interest.

\section{References}

Akkurt I, Akyıldırım H, Mavi B, Kılınçarslan Ş, Basyigit C (2012) The effect of pumice rate on the gamma absorption parameters of concrete. Acta Physica Polonica-Series A General Physics 121:144-146. https://doi.org/10.12693/APhysPolA.121.144

Arnoult M, Perronnet M, Autef A, Rossignol R (2018) How to control the geopolymer setting time with the alkaline

511 ASTM C348-14 Standard test method for flexural strength of hydraulic-cement mortars. In: ASTM International.

512 ASTM C349-14 Standard test method for compressive strength of hydraulic-cement mortars (Using Portions of Prisms 513 Broken in Flexure). In: ASTM International.

514 ASTM C618 Standard specification for coal fly ash and raw or calcined natural pozzolan for use as a mineral admixture 515 in concrete, In: ASTM International. 
Aygün B (2019) Neutron and gamma radiation shielding properties of high-temperature-resistant heavy concretes including chromite and wolframite. J Radiat Res Appl Sci 12:352-359. https://doi.org/10.1080/16878507.2019.1672312

Basyigit C, Uysal V, Kilincarslan Ş, Mavi B, Günoğlu K, Akkurt I, Akkaş A (2011) Investigating radiation shielding properties of different mineral origin heavyweight concretes. In: AIP conference proceedings 1400:232-235. American Institute of Physics. https://doi.org/10.1063/1.3663119

Champion B, Strzebonski A (2008) Constrained optimization. Wolfram Mathematica Tutorial Collection, USA

Chindaprasirt P, De Silva P, Hanjitsuwan S (2014) Effect of high-speed mixing on properties of high calcium fly ash geopolymer paste. Arab J Sci Eng 39:6001-6007. https://doi.org/10.1007/s13369-014-1217-1

Dadsetan S, Siad H, Lachemi M, Sahmaran M (2019) Construction and demolition waste in geopolymer concrete technology: A review. Mag Concr Res 71:1232-1252. https://doi.org/10.1680/jmacr.18.00307

Davidovits J (1979) SPE PACTEC'79. Society of Plastic Engineers, Brookfield Center, USA.

Davidovits J (2020) Geopolymer chemistry and applications. 5 $^{\text {th }}$ ed. Geopolymer Institute, Saint-Quentin, France.

Demirel Y (2015) Farklı beton dayanımlarındaki kolonlarda, eksenel yük seviyelerine göre geri sıçramalı çekiç verilerinin korelasyonu için deneysel bir öneri. Düzce Üniversitesi Bilim ve Teknoloji Dergisi 3:76-87.

Diaz EI, Allouche EN, Eklund S (2010) Factors affecting the suitability of fly ash as source material for geopolymers. Fuel 89:992-996. https://doi.org/10.1016/j.fuel.2009.09.012

Djobo JNY, Elimbi A, Tchakouté HK, Kumar S (2017) Volcanic ash-based geopolymer cements/concretes: the current state of the art and perpectives. Environ Sci Pollut Res 24:4433-4446. https://doi.org/10.1007/s11356-016-8230-8

Evcin A, Çelen YY, Bezir NÇ, Ersoy B (2018) Use of ilmenite and boron waste as a radiation shielding panel. In: AIP Conference Proceedings 2042:020001. AIP Publishing LLC.

Fatih T, Umit, A. (2001). Utilization of fly ash in manufacturing of building bricks. In: International ash utilization symposium. Center for applied energy research, University of Kentucky Paper (Vol. 13).

Fernández-Jiménez A, Palomo A (2005) Composition and microstructure of alkali activated fly ash binder: Effect of the activator. Cem Concr Res 35:1984-1992. https://doi.org/10.1016/j.cemconres.2005.03.003

Gorhan G, Kahraman E, Baspınar MS Demir I (2008) Uçucu kül bölüm I: oluşumu, sınıflandırılması ve kullanımı. Yapı Teknolojileri Elektronik Dergisi 2:85-94.

Huseien GF, MirzaJ, Ismail M, Ghoshal SK, Hussein AA (2017) Geopolymer mortars as sustainable repair material: A comprehensive review. Renew Sust Energ Rev 80:54-74. https://doi.org/10.1016/j.rser.2017.05.076

Irico S, De Meyst L, Qvaeschning D, Alonso MC, Willar K, De Belie N (2020) Severe sulfuric acid attack on selfcompacting concrete with granulometrically optimized blast-furnace slag-comparison of different test methods. Materials 13:1-21. https://doi.org/10.3390/ma13061431

Koumoto T (2019) Production of high compressive strength geopolymers considering fly ash or slag chemical composition. J Mater Civ Eng 31:06019006. https://doi.org/10.1061/(ASCE)MT.1943-5533.0002788

Kubissa W, Glinicki, MA, Dąbrowski M (2018) Permeability testing of radiation shielding concrete manufactured at industrial scale. Mater Struct 51: 83. https://doi.org/10.1617/s11527-018-1213-0

Kurtoğlu AE, Alzeebaree R, Aljumaili O, Niş A, Gülşan ME, Humur G, Çevik A (2018) Mechanical and durability properties of fly ash and slag based geopolymer concrete. Adv Concr Constr 6:345-362. 
https://doi.org/10.12989/acc.2018.6.4.345

Luhar S, Luhar I (2020) Fly ash based geopolymer mortar-strength performance. Int J Recent Technol (IJRTE) 8:11811186. ISSN: 2277-3878.

Mermerdaş K, Manguri S, Nassani DE, Oleiwi SM (2017) Effect of aggregate properties on the mechanical and absorption characteristics of geopolymer mortar. Eng Sci Technol Int J 20:1642-1652. https://doi.org/10.1016/j.jestch.2017.11.009

Mohammed KS, Azeez AB, Al Bakri AMM, Hussin K, Rahmat AB (2014) The effect of barite content on anti radiation properties of geopolymer fly ash concrete incorporated natural rock ores of hematite. Int J Sci Res 3:1818-1827. ISSN: 2319-7064

Okoye FN, Durgaprasad J, Singh NB (2016) Effect of silica fume on the mechanical properties of fly ash basedgeopolymer concrete. Ceram Int 42:3000-3006. https://doi.org/10.1016/j.ceramint.2015.10.084

Pacheco-Torgal F, Castro-Gomes J, Jalali S (2008) Alkali-activated binders: A review: Part 1. Historical background, terminology, reaction mechanisms and hydration products. Constr Build Mater 22:1305-1314. https://doi.org/10.1016/j.conbuildmat.2007.10.015

Sagoe-Crentsil K, Weng L (2007) Dissolution processes, hydrolysis and condensation reactions during geopolymer synthesis: Part II. High Si/Al ratio systems. J Mater Sci 42: 3007-3014. https://doi.org/10.1007/s10853-006-08189

Shalbi SM, Jaafar MS, Ahmed NM, Al-Jarrah AM, Naji A, Alsadig Ahmed A, Qaeed MA (2017) Effect of fly ash geopolymer with $15 \%$ barium sulphate as a design shielding box on radiation attenuation using GafchramicXRQA2 film dosimetry. IOSR J Eng (IOSRJEN) 7:13-17. ISSN: 2250-3021

Somna K, Jaturapitakkul C, Kajitvichyanukul P, Chindaprasirt P (2011) NaOH-activated ground fly ash geopolymer cured at ambient temperature. Fuel 90:2118-2124.

Storn R, Price KV (1997) Differential evolution-A simple and efficient the heuristic for global optimization over continuous spaces. J Global Optim 11:341-359. https://doi.org/10.1023/A:1008202821328

Tamzok N (2017) Yerli kömüre dayalı termik santral potansiyeli, darboğazlar ve çözüm önerileri, Türkiye’de Termik Santraller. TMMOB Yayın No: 668:135-142.

TS EN 196-1 Methods of testing cement-part 1: determination of strength, In: Turkish Standards.

TS EN 933-10 Tests for geometrical properties of aggregates-part 10: assessment of fines-grading of filler aggregates (Air Jet Sieving), In: Turkish Standards.

Uzun I, Nümerik Analiz (2011), In: Beta Basım A.Ş, Turkey, in Turkish.

Weng L, Sagoe-Crentsil K (2007) Dissolution processes. hydrolysis and condensation reactions during geopolymer synthesis: Part I-Low Si/Al ratio systems. J Mater Sci 42: 2997-3006. https://doi.org/10.1007/s10853-006-0820-2

Wolfram Research, Mathematica Edition, Version 11.0 (2016) Wolfram Research. Champaign, Illinois, USA.

Yalcin (2020) Laboratuvar ortamında beton üretimi. http://insaat.eskisehir.edu.tr/muhsiny/MLZ204/icerik/10H2)\%20Beton\%20deneyleri-1.pdf. Accessed 9 Jan 2021 


\section{Figures}
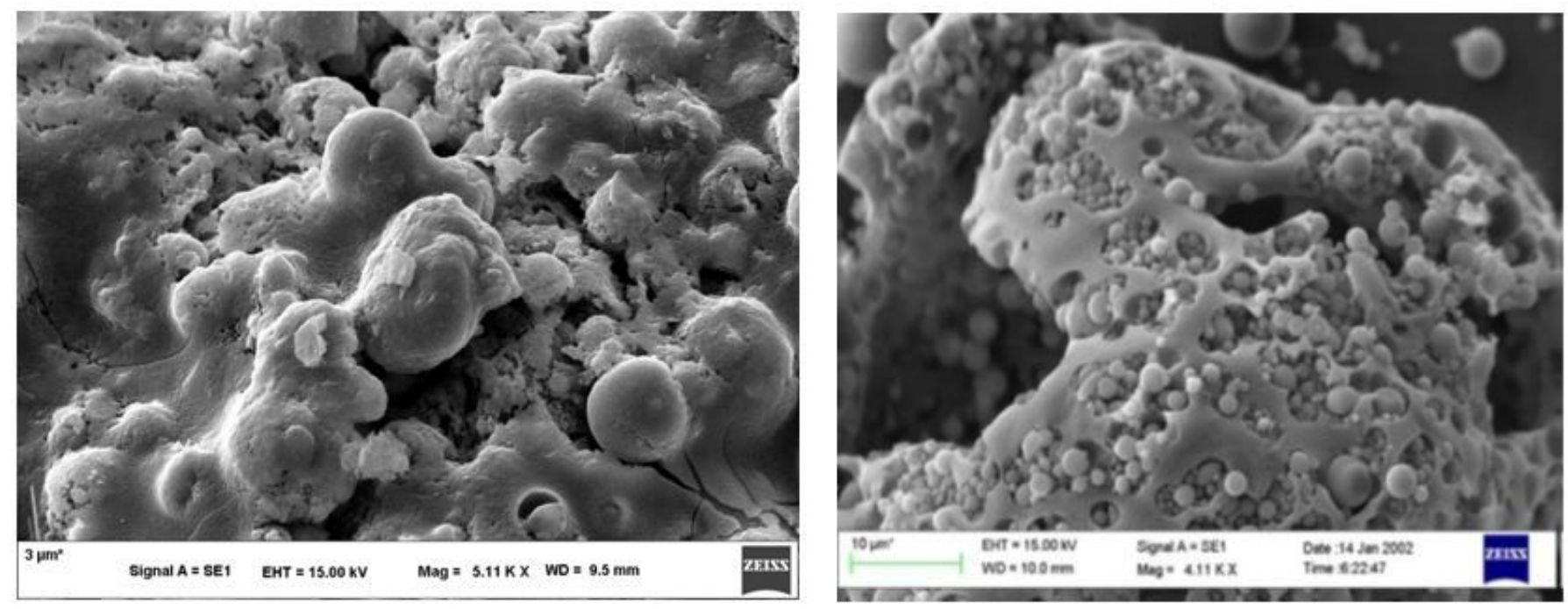

Figure 1

Zeiss SEM image of CTPP FFA (left) and ISTPP FFA (right)

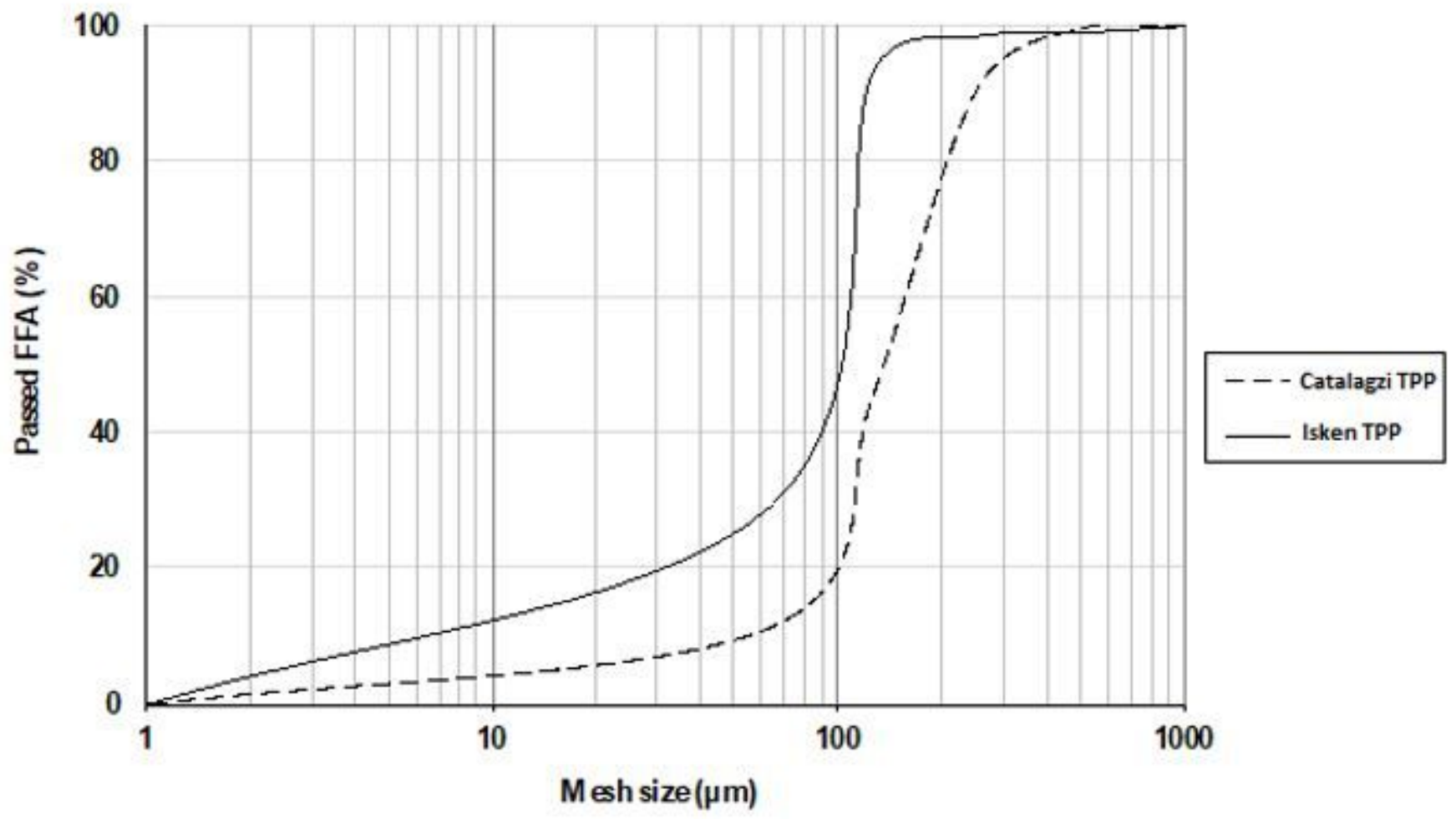

Figure 2 
Granulometric distribution of the FFAs

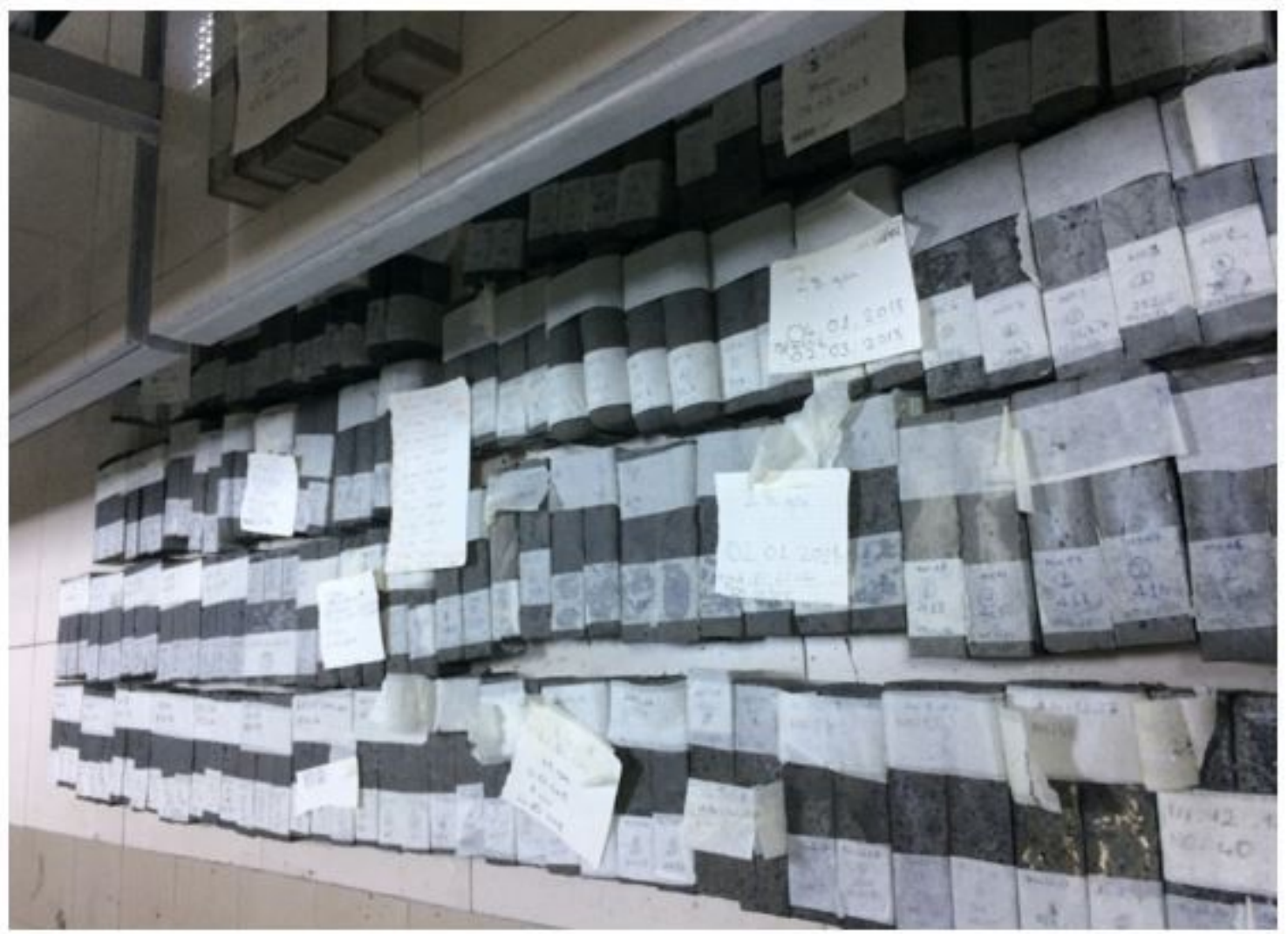

Figure 3

Some GPBMs produced in this study.

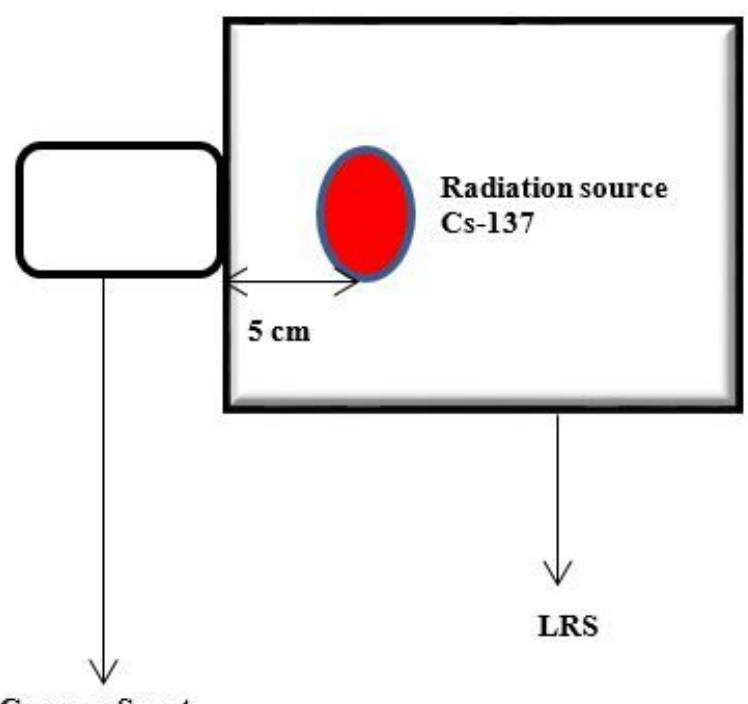

Gamma-Scout

Geiger Muller Counter

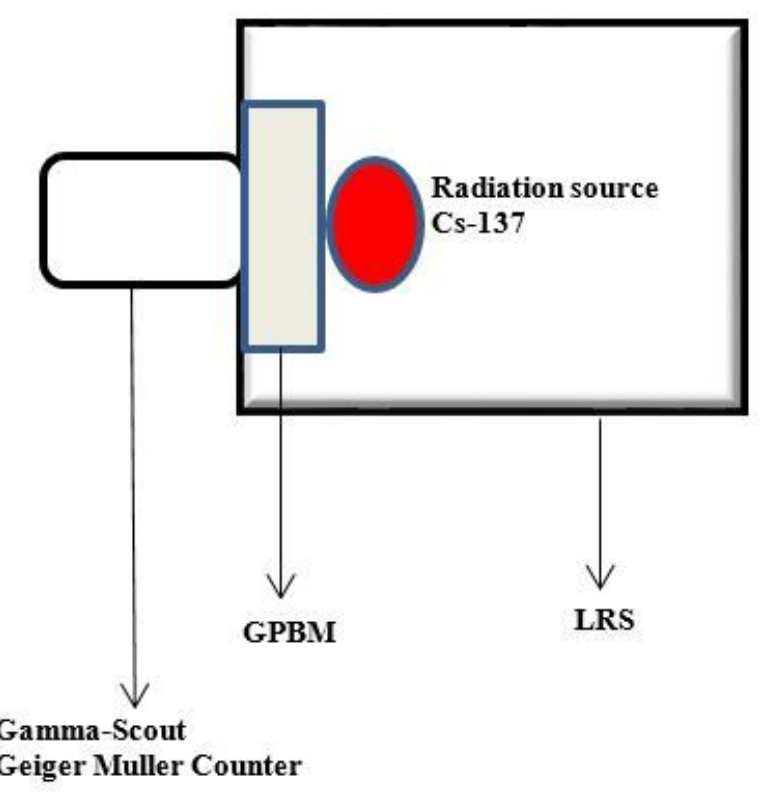


Figure 4

Experimental-setup (Schematic representation) of RA measurement system

a)

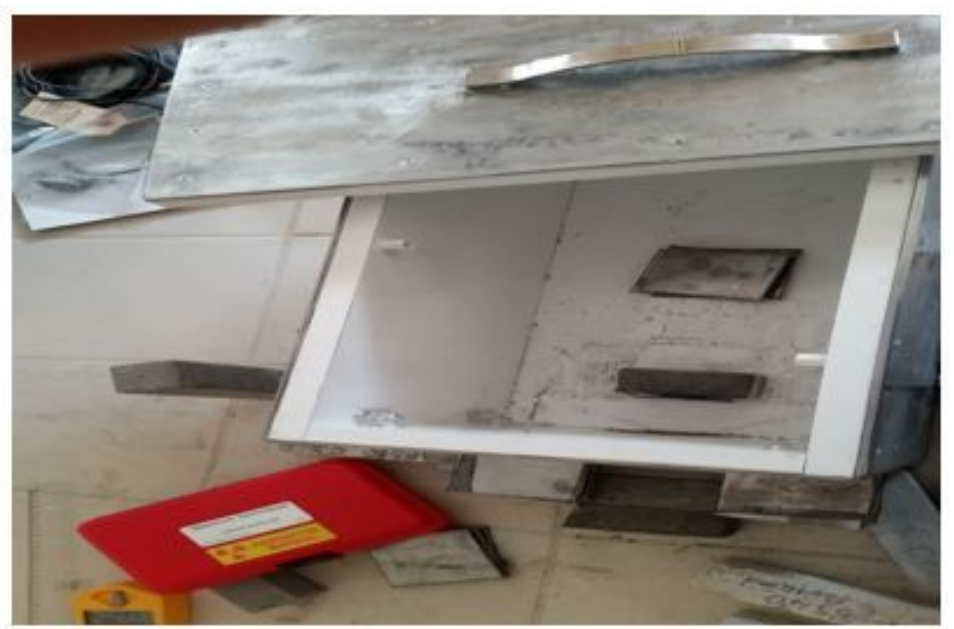

b)

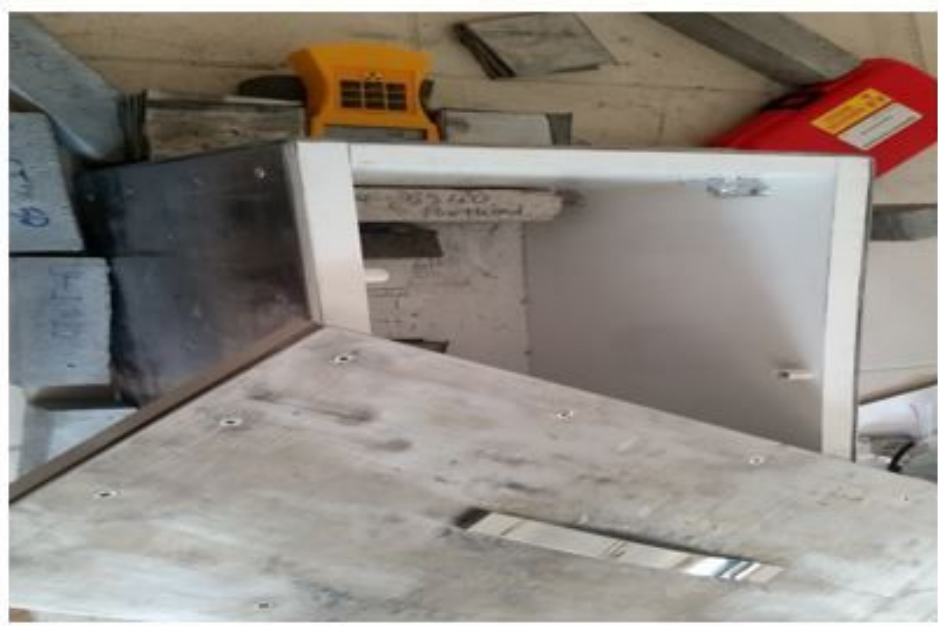

c)

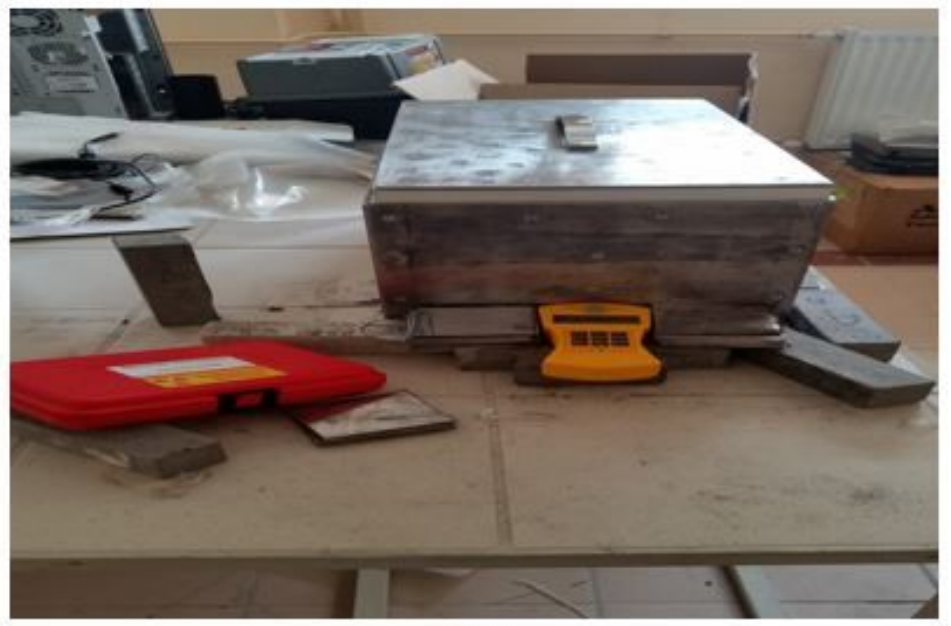

Figure 5

Newly designed LRS cage RA measurement system used in this study. 
(a)

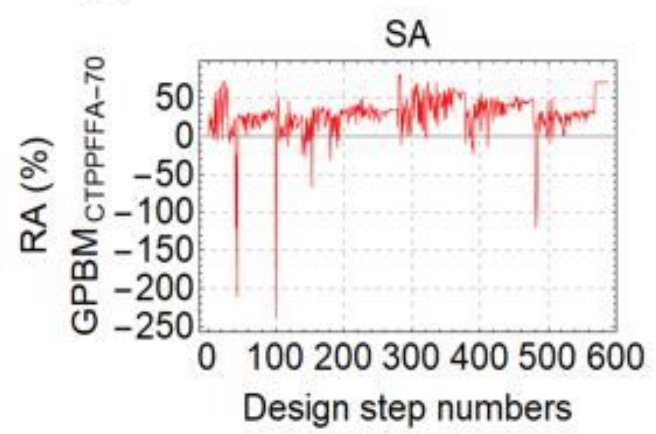

(c)

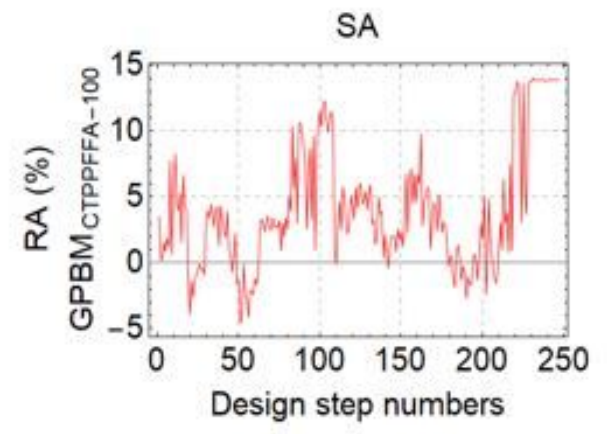

(e)

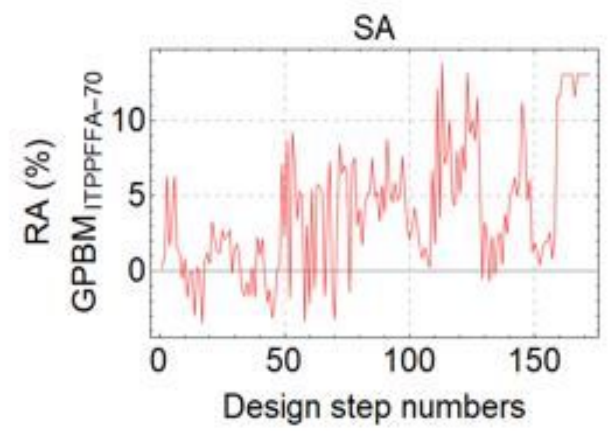

(g)

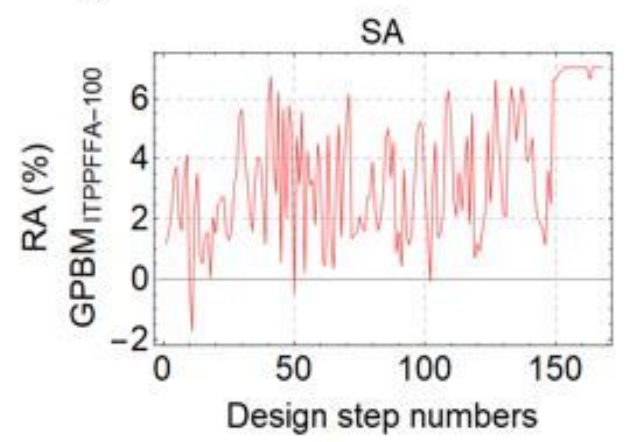

(b)

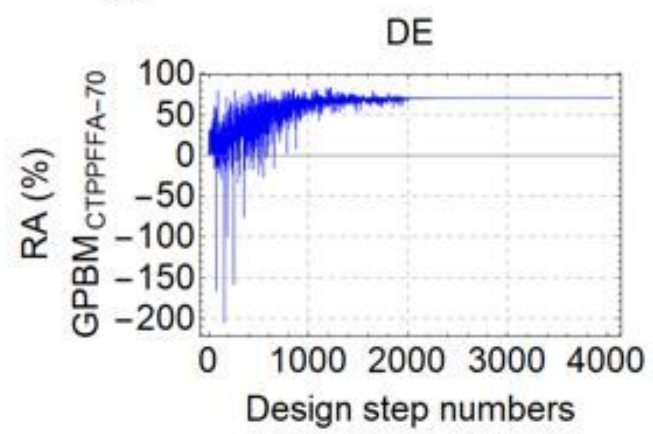

(d)

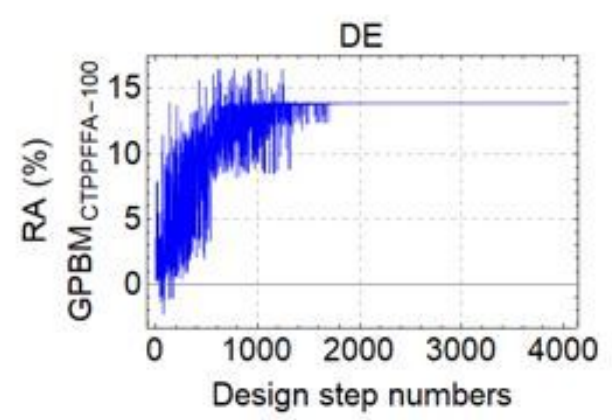

(f)

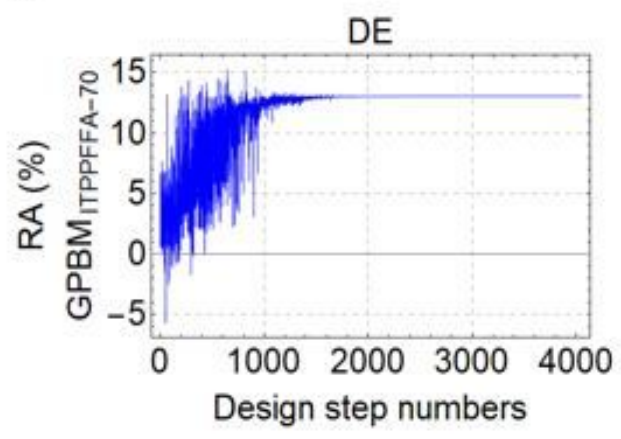

(h)

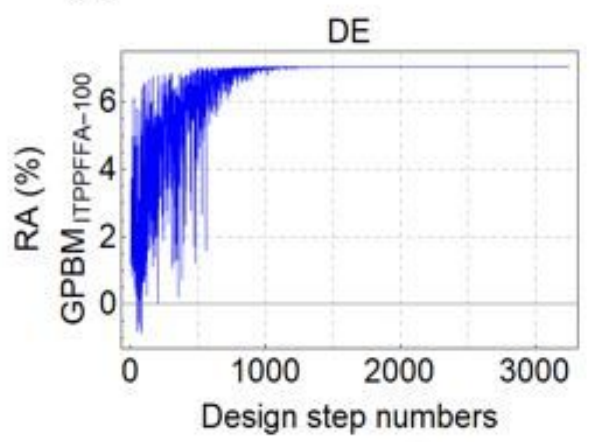

\section{Figure 6}

RA (\%) optimization process with respect to design step numbers by using simulated annealing (SA) and differential evolution (DE) methods considering GPBM produced from Catalagzi TPP in curing temperature of 70 oC (GPBMCTPPFFA-70; $a, b)$ and 100 oC (GPBMCTPPFFA-100; $c, d$ ), from Isken TPP in curing temperature of 70 oC (GPBMITPPFFA-100; e, f) and 100 oC (GPBMITPPFFA-100; $g, \mathrm{~h}$ ) 


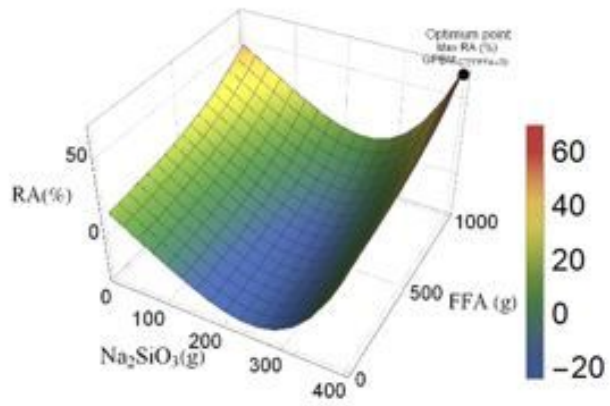

(c)

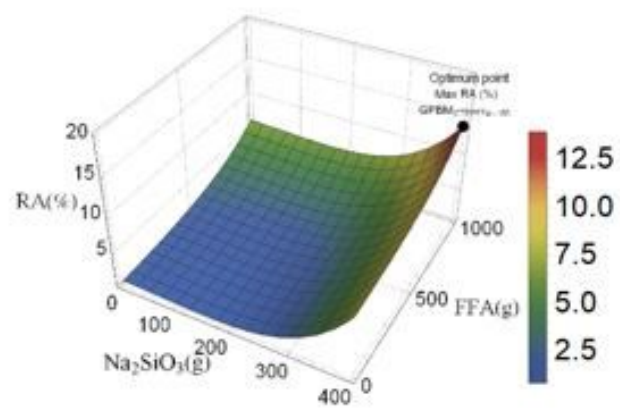

(e)

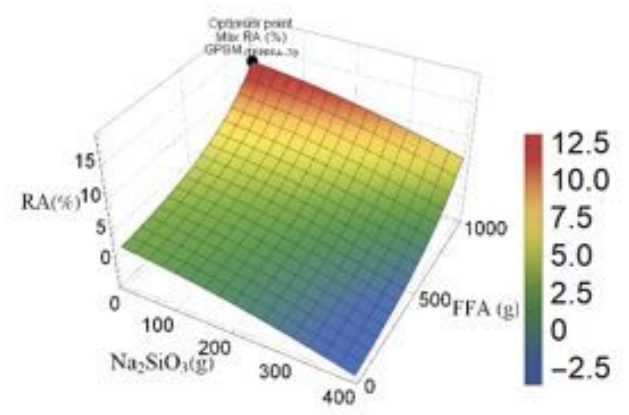

(g)

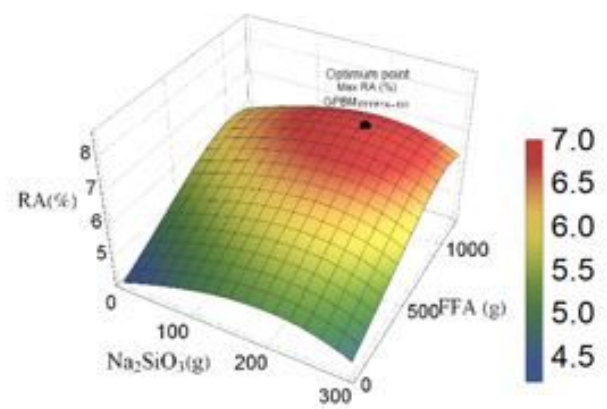

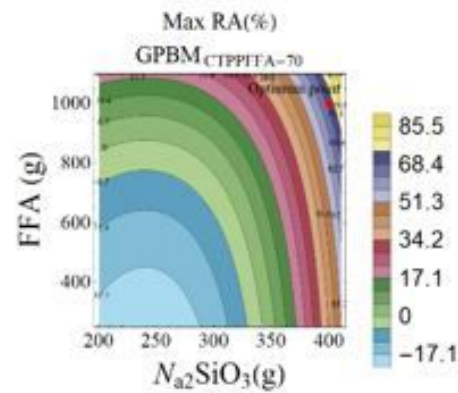

(d)

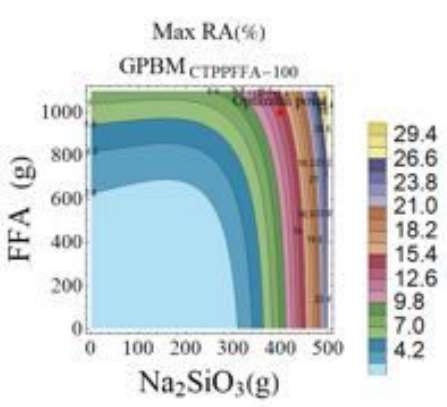

(f)

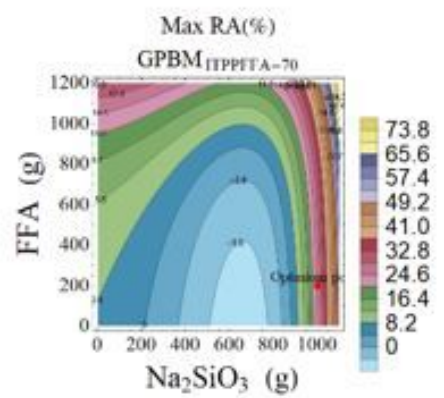

(h)

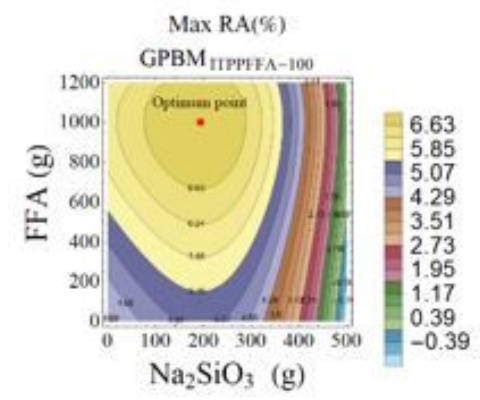

\section{Figure 7}

Variation of RA (\%) as three dimension and contour plot graph with respect to $\mathrm{Na2SiO3} \mathrm{and} \mathrm{FFA}$ quantities for GPBMCTPPFFA-70 (a, b), GPBMCTPPFFA-100 (c, d), GPBMITPPFFA-70 (e, f), GPBMITPPFFA-100 $(\mathrm{g}, \mathrm{h})$

\section{Supplementary Files}


This is a list of supplementary files associated with this preprint. Click to download.

- GraphicalAbstractESPR.jpg

- Table3.jpg 